07;08;09

\title{
Направленное излучение нитевидных нанокристаллов GaAs/AIGaAs, легированных бериллием
}

\author{
(C) В.Г. Талалаев ${ }^{1,2}$, В.И. Штром ${ }^{2-5}$, Ю.Б. Самсоненко ${ }^{3,5}$, \\ А.И. Хребтов ${ }^{3}$, А.Д. Буравлев ${ }^{2-5}$, Г.Э. Цырлин ${ }^{3,5-7, \text { व }}$ \\ ${ }^{1}$ Martin Luther University Halle-Wittenberg, Halle, Germany \\ ${ }^{2}$ Санкт-Петербургский государственный университет, Санкт-Петербург, \\ Россия \\ ${ }^{3}$ Санкт-Петербургский академический университет РАН, Санкт-Петербург, \\ Россия \\ ${ }^{4}$ Физико-технический институт им. А.Ф. Иоффе РАН, Санкт-Петербург, \\ Россия \\ ${ }^{5}$ Институт аналитического приборостроения РАН, Санкт-Петербург, \\ Россия \\ ${ }^{6}$ Санкт-Петербургский национальный исследовательский университет \\ информационных технологий, механики и оптики, Санкт-Петербург, \\ Россия \\ ${ }^{7}$ Санкт-Петербургский политехнический университет Петра Великого, \\ Санкт-Петербург, Россия \\ ๑ E-mail: cirlin@beam.ioffe.ru
}

\section{Поступило в Редакцию 28 сентября 2016 г.}

Проведены исследования направленности излучения самокаталитических нитевидных нанокристаллов (НHК) типа НHК GaAs в оболочке AlGaAs, полученных методом молекулярно-пучковой эпитаксии с разной степенью легирования бериллием. Показано, что нелегированный образец обладает выраженными волноводными свойствами вдоль направления роста. При увеличении степени легирования возрастает интенсивность излучения, направленного перпендикулярно боковым стенкам ННК.

DOI: 10.21883/PJTF.2017.17.44949.16504

В настоящее время интенсивно исследуются свойства нитевидных кристаллов нанометрового сечения (ННК), в том числе преднамеренно легированных. Это связано с возможностью реализации на основе ННК различных приборных компонентов, в том числе солнечных элемен- 
тов, транзисторов, лазеров, светодиодов, детекторов и т.п. [1]. Для оптоэлектронных приложений структуры типа HHK GaAs в оболочке AlGaAs имеют значительный потенциал в связи с наличием широкозонного покрывающего слоя, эффективно подавляющего процессы безызлучательной рекомбинации, связанные с высокой плотностью поверхностных состояний в HНК GaAs [2-4]. Кроме того, подобная геометрия ННК открывает новые возможности инженерии электронной структуры в радиальных гетероструктурах $[5,6]$. Исследование интенсивности направленного излучения как массивов вертикально стоящих, так и одиночных ННК имеет принципиальное значение для улучшения эффективности оптоэлектронных приборов. В работах [7-9] продемонстрированы приборные конструкции с $p-n$-переходами на основе ННК. При их создании ННК легируют примесями $p$ - или $n$-типа (например, Be или $\mathrm{Si}$ соответственно). Как было показано, оптические свойства ННК зависят от концентрации легирующей примеси [10]. Однако вопрос о влиянии примесей на направленность излучения в ННК на данный момент практически не исследован. Настоящая работа посвящена исследованию диаграммы направленности излучения ближнего ИК-диапазона в самокаталитических НHK GaAs/AlGaAs, легированных Ве с различной концентрацией.

Ростовые эксперименты проводились на установке ЭП 1203, оснащенной различными эффузионными источниками, в том числе алюминия, галлия, мышьяка и бериллия. Для исследования поверхности во время роста использовался метод дифракции быстрых электронов на отражение (ДБЭО). В качестве подложек использовались полированные полуизолирующие пластины кремния с ориентацией поверхности (111). Выращивание производилось по методике самокаталитического роста, разработанной авторами [11]. После удаления окисного слоя с поверхности подложки проводилось напыление слоя галлия толщиной $\sim 2 \mathrm{~nm}$ в отсутствие потока мышьяка к поверхности. После минутной выдержки для создания более равномерных эвтектических капель $\mathrm{Ga}$ открывались заслонки As и $\mathrm{Be}$ (в качестве легирующей примеси $p$-типа в случае легированных НHК) и производилось выращивание HHK GaAs. Картины ДБЭО свидетельствовали об образовании кубической фазы НHК уже после напыления $50 \mathrm{~nm}$. Далее заслонка $\mathrm{Al}$ открывалась для формирования покрывающего слоя $\mathrm{AlGaAs}$ (с закрытой заслонкой бериллия). Концентрации дырок в ядре ННК, определенные по росту

Письма в ЖТФ, 2017, том 43, вып. 17 
планарных слоев GaAs:Be, соответствовали $5 \cdot 10^{16}$ и $5 \cdot 10^{19} \mathrm{~cm}^{-3}$ (низколегированный и высоколегированный режимы соответственно).

Для подготовки образцов для измерений массивы ННК на подложке помещались в раствор этанола. Далее с помощью ультразвука ННК отделялись от подложки и в капле переносились на поверхность кремния площадью $2 \times 2 \mathrm{~mm}$ (рис. $1, a$ ). Данные, полученные с помощью оптического микроскопа, позволили оценить геометрические размеры HНK GaAs/AlGaAs: длина - около $3 \mu \mathrm{m}$, диаметр - около $100 \mathrm{~nm}$.

Возбуждение спектров фотолюминесценции (ФЛ) осуществлялось несфокусированным поляризованным пучком аргонового лазера, падающим по нормали на поверхность подложки с неупорядоченно уложенными на ней ННК. Сбор сигнала ФЛ проводился в двух вариантах: по нормали к подложке (обычная, 180-градусная геометрия) и вдоль поверхности подложки (ортогональная, 90-градусная геометрия) (рис. $1, b)$. Во втором случае излучение ННК разворачивалось в направлении сбора сигнала с помощью позолоченной призмы, расположенной непосредственно вдоль вертикального торца подложки. Подложкодержатель с образцом и призмой помещался в оптический гелиевый криостат и охлаждался до температуры $10 \mathrm{~K}$. Спектры ФЛ возбуждались линией $488 \mathrm{~nm}$ аргонового лазера. Плотность возбуждения составляла $10 \mathrm{~W} / \mathrm{cm}^{2}$. Спектры ФЛ регистрировались охлаждаемым германиевым приемником. Поляризация излучения ННК не анализировалась. Дифракционная решетка монохроматора (600 lines $/ \mathrm{mm})$ имела близкую для $s$ - и $p$-поляризаций на анализируемой длине волны $(850 \mathrm{~nm})$ эффективность. Спектры ФЛ корректировались на спектральную чувствительность модуля регистрации. Кроме того, для ортогональной геометрии они умножались на коэффициент 2, учитывающий двукратное уменьшение телесного угла сбора сигнала ФЛ призмой. Потери сигнала на отражение от призмы не учитывались.

Результаты измерений ФЛ нелегированных ННК продемонстрировали высокую интенсивность при сборе сигнала вдоль поверхности подложки, в то время как сигнал, собираемый по нормали к подложке, был едва различим на уровне шумов (рис. 2,a). В этом случае можно предположить, что излучение от нелегированных ННК носит направленный, волноводный характер. Известно, что в случае симметричного волновода (когда слой с большим показателем преломления заключен между неограниченными слоями с меньшим показателем преломления) возможно существование мод электромагнитного излучения при сколь

Письма в ЖТФ, 2017, том 43, вып. 17 


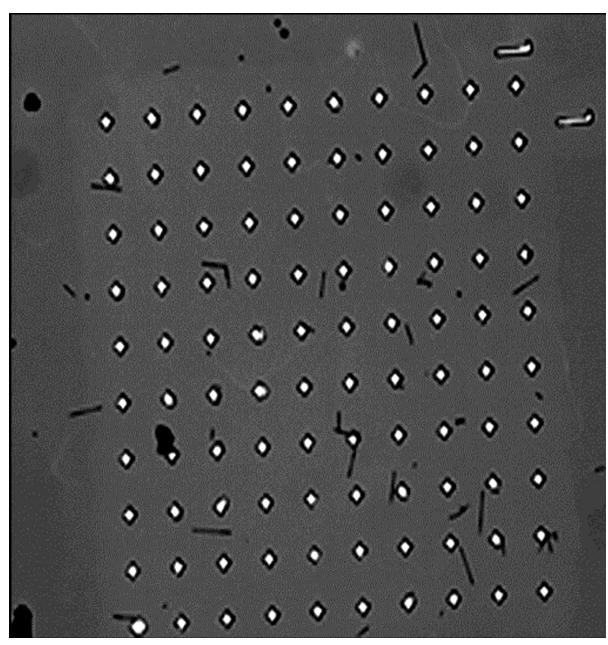

\section{$a$}

$b$

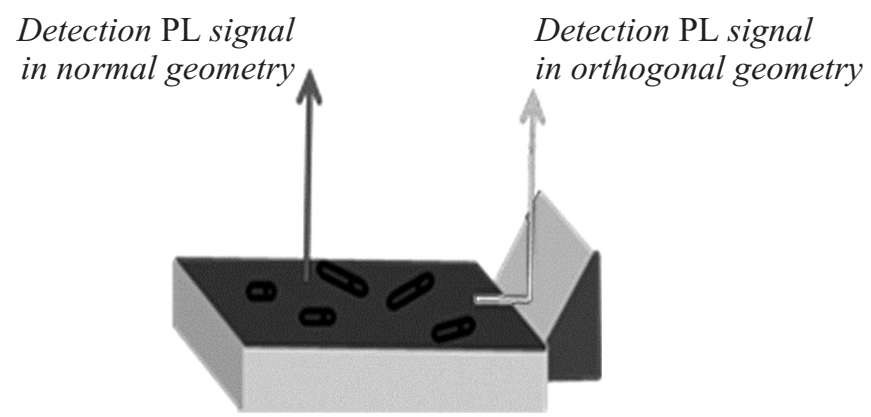

Рис. 1. $a$ - изображение НHК GaAs/AlGaAs на поверхности кремния, полученное с помощью оптического микроскопа с 150 -кратным увеличением. $b-$ схема детектирования сигнала ФЛ от ННК в двух вариантах: по нормали к подложке (обычная, 180-градусная геометрия) и вдоль поверхности подложки (ортогональная, 90-градусная геометрия).

угодно малой толщине волновода [12,13]. Следовательно, электромагнитная мода может быть локализована в окрестности волноводного 
слоя, толщина которого меньше длины волны самой моды. В нашем случае возбуждающее излучение аргонового лазера проникает в ядро ННК через слой пассивирующей оболочки AlGaAs толщиной около $20 \mathrm{~nm}$ с меньшим показателем преломления, чем в GaAs. После этого излучение, многократно отражаясь на границе GaAs-ядро/AlGaAs-оболочка, выходит из торца ННК. В этом случае излучение ННК с диаметром сердцевины GaAs 50-60 nm и длиной $3 \mu \mathrm{m}$ соответствует поведению симметричного волновода [12]. Исчезновение сигнала ФЛ в такой геометрии от массива нелегированных ННК подтверждает сделанное предположение о волноводном распространении излучения вдоль оси роста ННК.

На рис. 2 также показаны спектры ФЛ образцов с ННК, легированными бериллием с концентрациями $\sim 10^{16}(b)$ и $\sim 10^{19} \mathrm{~cm}^{-3}(c)$, при двух вариантах детектирования сигнала. В случае образца с меньшей концентрацией примеси интенсивность ФЛ при сборе сигнала в обычной, 180-градусной геометрии была в 5 раз меньше, чем при сборе сигнала в ортогональной геометрии с призмой. При этом положение максимума ФЛ составляло $831 \mathrm{~nm}$ (рис. 2, $b$ ). Для образца с высокой степенью концентрации бериллия наблюдалась обратная картина: интенсивность ФЛ при сборе сигнала по нормали к подложке была в 6 раз больше, чем в случае ортогонального варианта детектирования (рис. 2,c). Максимум ФЛ в обоих вариантах находился вблизи $836 \mathrm{~nm}$. Остановимся подробнее на поведении ФЛ в легированных образцах. Максимумы линий ФЛ имеют характерный „красный“ сдвиг относительно максимума нелегированного $\mathrm{GaAs}(820 \mathrm{~nm}$ при $T=10 \mathrm{~K})$. С увеличением концентрации Ве от $10^{16}$ до $10^{19} \mathrm{~cm}^{-3}$ максимум сдвигается последовательно в положение 831 и $836 \mathrm{~nm}$ соответственно, что отвечает сдвигу полосы ФЛ в легированных слоях GaAs [14]. Характер изменения интенсивности ФЛ от легированных ННК при двух различных способах сбора сигнала мы связываем с рассеянием возбуждающего излучения на примесях внутри HHK GaAs [15]. Действительно, при малой концентрации бериллия наблюдается преобладание сигнала, собираемого вдоль поверхности подложки, хотя и не столь явное, как в случае нелегированных ННК. Часть сигнала излучения рассеивается на примесных центрах и выходит по нормали к подложке (рис. 2, $b$ ). В случае многократного увеличения примесных центров $\left(N_{\mathrm{Be}}=10^{19} \mathrm{~cm}^{-3}\right)$ рассеяние излучения с последующим выходом по 


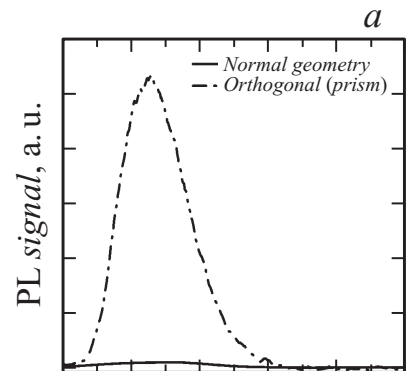

800820840860880900 Wavelength, nm

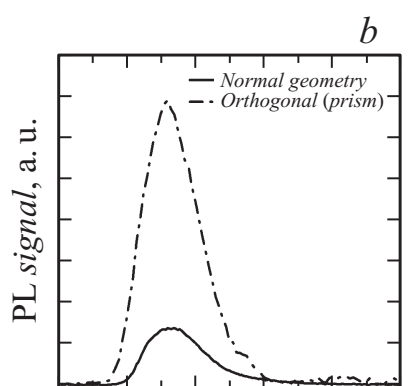

800820840860880900 Wavelength, $\mathrm{nm}$

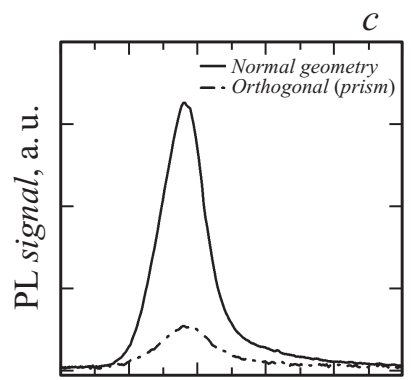

800820840860880900

Wavelength, nm

Рис. 2. Спектры ФЛ образцов с нелегрованными ННК (a), а также легированными бериллием с концентрациями $10^{16}(b)$ и $10^{19} \mathrm{~cm}^{-3}(c)$ при двух вариантах детектирования сигнала в нормальной геометрии и ортогональной с помощью призмы.

нормали к подложке преобладает над излучением, выходящим из торцов ННК вдоль поверхности подложки (рис. 2,c).

Таким образом, в работе впервые продемонстрированы волноводные свойства НHК GaAs/AlGaAs для света ближнего ИК-диапазона и показана зависимость этих свойств от степени легирования ННК. Следовательно, нитевидные нанокристаллы вследствие своих геометрических параметров (симметричность, диаметр 10-100 nm, длина 1-20 $\mu \mathrm{m}$ ) являются перспективными объектами для использования их в качестве наноисточников направленного излучения.

Письма в ЖТФ, 2017, том 43, вып. 17 
Образцы были синтезированы и измерены за счет гранта Российского научного фонда (проект № 14-12-00393). Подготовка образцов для измерений проводилась при финансовой поддержке СПбГУ (НИР № 11.37.210.2016). Работа выполнена при частичной поддержке гранта РФФИ 16-29-03113-офи.

\section{Список литературы}

[1] Дубровский В.Г., Цырлин Г.Э., Устинов В.М. // ФТП. 2009. Т. 43. В. 12. C. $1585-1628$.

[2] Tomioka K., Kobayashi Y., Motohisa J. et al. // Nanotechnology. 2009. V. 20. N 14. P. 145302.

[3] Titova L.V., B.Hoang T., Jackson H. E. et al. // Appl. Phys. Lett. 2006. V. 89. P. 173126.

[4] Durand C., Bougerol C., Carlin J.-F. et al. // ACS Photon. 2014. V. 1. P. 38-46.

[5] Dimakis E., Jahn U., Ramsteiner M. et al. // Nano Lett. 2014. V. 14. P. 2604-2609.

[6] Weiss M., Kinzel J.B., Schuelein F.J.R. et al. // Nano Lett. 2014. V. 14. P. 2256-2264.

[7] Tchernycheva M., Rigutti L., Jacopin G. et al. // Nanotechnology. 2012. V. 23. P. 265402.

[8] Cirlin G.E. et al. // Nanoscale Res. Lett. 2010. V. 5. N 2. P. 360-363.

[9] Григорьев Р.В., Штром И.В. и др. // Письма ЖТФ. 2015. Т. 41. В. 9. C. $71-79$.

[10] Senichev A.V., Talalaev V.G. et al. // ACS Photon. 2014. V. 1. N 11. P. 1099-1106.

[11] Cirlin G.E., Dubrovskii V.G. et al. // Phys. Rev. B. 2010. V. 82. N 3. P. 035302.

[12] Yariv A., Yeh P. Optical waves in crystals. N. Y. : John Wiley \& Sons, Inc., 1984. $589 \mathrm{p}$.

[13] Алешкин В.Я., Афоненко А.А. и др. // ФТП. 2013. Т. 47. В. 11. С. 1486-1488.

[14] Zhang D.H. et al. // J. Cryst. Growth. V. 148. N 1. P. 35-40.

[15] Введение в интегральную оптику / Под ред. М. Барноски. М.: Мир, 1977. $367 \mathrm{c}$.

Письма в ЖТФ, 2017, том 43, вып. 17 